\title{
Association between Toll-like receptor 7 Gln11Leu single-nucleotide polymorphism and basal cell carcinoma
}

\author{
IRENE RUSSO $^{1}$, CAMILLA CONA $^{2}$, ANDREA SAPONERI $^{1}$, FRANCO BASSETTO $^{2}$, \\ VINCENZO BALDO ${ }^{3}$ and MAURO ALAIBAC ${ }^{1}$ \\ ${ }^{1}$ Dermatology Unit, Department of Medicine, University of Padova, I-35121 Padova; ${ }^{2}$ Plastic Surgery Unit, \\ University of Padova, I-35128 Padova; ${ }^{3}$ Public Health Unit, University of Padova, I-35121 Padova, Italy
}

Received October 1, 2015; Accepted January 19, 2016

DOI: 10.3892/br.2016.597

\begin{abstract}
Non-melanoma skin cancers (NMSC) are the most common form of human skin cancer. The majority of NMSC are basal cell carcinoma (BCC) and squamous cell carcinoma (SCC) with a BCC:SCC incidence ratio of 4:1 in immunocompetent patients. Toll-like receptors (TLRs) are transmembrane glycoproteins that recognize pathogen-associated molecular patterns and damage-associated molecular patterns, against which they activate the innate immune response and initiate the adaptive immune response. Genetic variations of these receptors can alter the immune system and are involved in evolution and susceptibility of various diseases, including cancer. Imiquimod, an agonist of TLR7, is applied topically in the treatment of premalignant and malignant skin disorders, in particular BCC. The high efficacy of this TLR7 agonist toward BCC supports a possible role of this receptor in the induction of BCC and, consequently, polymorphisms of this receptor could be responsible for a greater or lesser susceptibility to BCC. The aim of the present study was to evaluate whether the presence of the functional TLR7 rs179008/Gln11Leu promoter polymorphism conferred an increased susceptibility to BCC. A case-control study with 177 BCC cases and 158 controls was performed to highlight the possible association between this polymorphism and the susceptibility to BCC. As the TLR7 gene is localized on chromosome $\mathrm{X}$, the allelic frequency of this polymorphism was analyzed separately in males and females. The analysis of the distribution of frequencies of wild-type TLR7 and variant $T L R 7$ carrying the single-nucleotide polymorphism (SNP) rs179008 in patients with BCC and healthy subjects did not reveal any statistically significant difference between cases and controls. This study does not suggest the involvement of
\end{abstract}

Correspondence to: Professor Mauro Alaibac, Dermatology Unit, Department of Medicine, University of Padova, Via Battisti 206, I-35121 Padova, Italy

E-mail: mauro.alaibac@unipd.it

Key words: skin cancer, basal cell carcinoma, Toll-like receptors, polymorphisms, cancer susceptibility the SNP rs179008 of TLR7 in the susceptibility to BCC, but cannot exclude a role for TLR7 in BCC carcinogenesis considering the high efficacy of the TLR7 agonist, imiquimod, in the treatment of this neoplastic disorder.

\section{Introduction}

Non-melanoma skin cancers (NMSC) are the most common form of human skin cancer. The majority of NMSC are basal cell carcinoma (BCC) and squamous cell carcinoma (SCC) with a BCC:SCC incidence ratio of 4:1 in immunocompetent patients (1). NMSC are an increasing problem for health care services worldwide. Incidence rates of NMSC continue to increase, possibly due to a combination of factors, notably an increased exposure to sunlight and ultraviolet (UV) radiation, increased longevity, ozone depletion and in certain cases, immunosuppression.

BCC accounts for $80 \%$ of NMSC (2) and has become more frequent in younger patients ( $<40$ years) although the average age at first diagnosis is $\sim 60$ years (3). The major established environmental risk factors for BCC are skin type and exposure to UV radiation. Other risk factors include immunosuppression, exposure to arsenic, scars and hereditary disorders such as nevoid BCC syndrome (Gorlin-Goltz syndrome) and xeroderma pigmentosum (4). Although there are numerous histological subtypes, a simplified classification divides all BCC into three histological subtypes: Superficial, nodular and infiltrative (5). BCCs have an extremely low metastatic potential and in the majority of cases they may be treated with local therapies, notably surgical excision, photodynamic therapy, cryotherapy or topical imiquimod (6).

Toll-like receptors (TLRs) constitute a family of receptors that directly recognize a wide spectrum of exogenous ligands [pathogen-associated molecular patterns (PAMPs)] and endogenous damage-associated molecular patterns (DAMPs) (7). The human TLR family consists of $\geq 10$ members: TLR1, 2, 4, 5,6 and 10 are usually expressed on the cell surface, whereas TLR3, 7, 8 and 9 are mainly expressed on the surfaces of endosomes, lysosomes and the endoplasmic reticulum (8). TLRs are implicated in the innate and adaptive immune response (9-11), and also in cellular proliferation, differentiation, mitosis, cell-cycle regulation, apoptosis, angiogenesis and tissue remodelling $(12,13)$. TLRs activate several signaling 
pathways that are responsible for the induction of nuclear transcription factors (14). Genes induced by the activation of TLRs encode for several inflammatory cytokines, notably tumor necrosis factor- $\alpha$ (TNF- $\alpha$ ), including interferon (IFN) 1 , interleukin-6 (IL-6), IL-1, granulocyte-colony stimulating factor, and different chemokines, including CCL2 and CXCL10 $(7,14)$. Certain TLRs have been associated with the pathogenesis of several inflammatory and autoimmune skin diseases (15). Furthermore, their role in tumor development and progression has attracted increasing attention recently (11). Imiquimod, an agonist of TLR7 (16) has been shown to induce the expression of several cytokines such as IFN- $\alpha$, IL-12 and TNF- $\alpha$, which mediate its anticancer effects (pro-apoptotic, anti-invasive and anti-angiogenic) (17). It may be applied topically in the treatment of premalignant and malignant skin disorders, in particular BCC $(17,18)$. The high efficacy of this TLR7 agonist toward BCC supports a possible role of this receptor in the induction of BCC, and consequently, polymorphisms of this receptor could be responsible for a greater or lesser susceptibility to BCC.

In the present study, a functional single-nucleotide polymorphism (SNP) within the promoter of TLR7 gene (SNP rs179008/Gln11Leu) was investigated in order to determine whether the carriers of this variant were more or less susceptible to BCC.

\section{Materials and methods}

Patients. A prospective case-control study with 177 cases of histologically confirmed BCC and 158 controls from healthy blood donors was performed. The study comprised 177 Caucasian patients who underwent surgical excision for BCC, 104 males and 73 females, with an average age of 76.8 years, were recruited at the Unit of Dermatology and the Unit of Plastic Surgery of the University of Padova (Padova, Italy) (Table I). Participants provided written informed consent and the study was approved by the local research ethics committee. Blood samples from 158 normal healthy Caucasian individuals, 69 males and 89 females, were used as the controls.

Polymorphism analysis. The TLR7 gene is located on chromosome Xp22.2. The TLR7 exon polymorphism SNP rs179008 $(\mathrm{A}>\mathrm{T})$, base pair 17,961 relative to start codon ATG on exon 3, was analyzed. DNA was extracted from a peripheral blood sample and the rs179008 TLR7-SNP genotyping was performed by TaqMan allelic discrimination using the assays C_2259574_10 (Applied Biosystems, Foster City, CA, USA). The two alleles were scored using primers and TaqMan minor groove binder probes labeled with VIC and FAM dye (forward, 5'-CTT TCA GGT GTT TCC AAT GTG GAC-3' and reverse primers, 5'-CCC CAA GGA GTT TGG AAA TTA GGA T-3'; probes, 5'-TGA AGA GAC AAA TTC-3' and 5'-ACT GAA GAG ACT AAT TC-3'; the underlined character indicates the polymorphism).

Polymerase chain reaction (PCR) was performed according to the manufacturer's protocols on the StepOnePlus ${ }^{\mathrm{TM}}$ Real-Time PCR system (Applied Biosystems).

Statistical analysis. The genotypes obtained were statistically analyzed by applying the $\chi^{2}$ test. The allele frequency
Table I. Distribution of patients and genotype frequencies of the TLR7 Gln11Leu single-nucleotide polymorphism.

\begin{tabular}{lcc}
\hline Polymorphism & $\begin{array}{c}\text { Basal cell } \\
\text { carcinoma, } \mathrm{n}(\%)\end{array}$ & $\begin{array}{c}\text { Controls } \\
\mathrm{n}(\%)\end{array}$ \\
\hline $\begin{array}{l}\text { TLR7 rs179008 }(\mathrm{A}>\mathrm{T}) \\
\text { Females }\end{array}$ & & \\
AA & $47(64.38)$ & $50(56.18)$ \\
AT & $19(26.03)$ & $37(41.57)$ \\
TT & $7(9.59)$ & $2(2.25)$ \\
Males & & \\
A & $82(78.85)$ & $57(82.61)$ \\
T & $22(21.15)$ & $12(17.39)$ \\
\hline
\end{tabular}

TLR7, Toll-like receptor 7 .

Table II. Allelic distribution of the TLR7 Gln11Leu single-nucleotide polymorphism.

\begin{tabular}{lcc}
\hline Polymorphism & $\begin{array}{c}\text { Basal cell } \\
\text { carcinoma, } \mathrm{n}(\%)\end{array}$ & $\begin{array}{c}\text { Controls } \\
\mathrm{n}(\%)\end{array}$ \\
\hline $\begin{array}{l}\text { TLR7 rs179008 (A>T) } \\
\text { Females }\end{array}$ & & \\
$\mathrm{A}$ & $113(77.40)$ & $137(76.97)$ \\
$\mathrm{T}$ & $33(22.60)$ & $41(23.03)$ \\
Males & & \\
A & $82(78.85)$ & $57(82.61)$ \\
T & $22(21.15)$ & $12(17.39)$ \\
Total A & 195 & 194 \\
Total T & 55 & 53 \\
\hline
\end{tabular}

TLR7, Toll-like receptor 7 .

of rs179008 TLR7, which is an X-linked gene, was analyzed separately for males and females, as well as overall frequency in the BCC patient and control groups.

\section{Results}

Distribution of allele frequencies between BCC cases and controls. No statistically significant differences were observed in the distribution of allele frequencies between the BCC cases and controls $(\mathrm{P}=0.97)$ (Table II). Similar results were identified in males $(\mathrm{P}=0.54)$ and females $(\mathrm{P}=0.93)$ (Table II). Therefore, the present results do not suggest the involvement of the SNP rs179008 of TLR7 in the susceptibility to BCC, but cannot exclude a role for TLR7 in BCC initiation and progression.

\section{Discussion}

The role of TLRs in cancer development and progression has been investigated previously. TLRs have been reported 
as expressed in different cancer cell lines and TLR polymorphisms have been associated with different types of neoplasms $(12,19,20)$. In healthy tissues, activation of TLRs may cause chronic inflammation, which has been demonstrated to represent a favorable environment for tumor initiation and progression (21-24). The role of TLRs in cancer is therefore ambiguous. TLRs have been found to be overexpressed in certain pre-malignant conditions and neoplasia (25-28), responsible for increasing angiogenic and metastatic potential of tumors activating nitric oxide synthase 2 and cyclooxygenase 2, and upregulating vascular endothelial growth factor and transforming growth factor- $\beta$ within the tumor microenvironment (29-31). By contrast, TLRs can cause tumor inhibition (32-35) and TLR ligands can have an anticancer effect, as demonstrated by studies on TLR7/8 and TLR9 agonists (36-38). In particular, TLR7 and TLR8 have emerged as key targets in immunotherapy. They are expressed on the endosomal surfaces of monocytes, macrophages, dendritic cells, B lymphocytes and mast cells (39). They induce the activation of nuclear factor- $\kappa \mathrm{B}$, which leads to the transcription of cytokines and chemokines through a myeloid differentiation protein 88-dependent pathway. Topical imiquimod was the first Food and Drug Administration approved drug acting as an agonist of TLR7 $(40,41)$. Several studies reported high efficacy of imiqimod for the treatment of superficial BCC with a cure rate ranging from 43-94\% (42-45), whereas it is less efficacious for nodular BCC with a cure rates of 50-65\% $(43,46)$. Imiquimod has also been used in the treatment of warts, actinic keratosis, Bowen's disease and lentigo maligna melanoma $(17,18)$. In addition to imiquimod, other topical agents, such as nicotinamide, all-trans retinoic acid, adapalene, zinc and sodium tosylchloramide have also been reported to act through TLRs (47).

Genetic variations in TLRs may alter host immune responses and lead to a different susceptibility to inflammatory disorders, autoimmune diseases and cancer (12). Certain TLR polymorphisms have been already analyzed in order to assess their impact on severity and prognosis of several autoimmune-inflammatory diseases and cancer (12). In the present study, the SNP rs179008 of the TLR7 gene, localized on chromosome X 22.2 at the ATG start codon of exon 3, was investigated. It is a functional non-synonymous polymorphism that consists in the replacement of an adenine with a thymine $(\mathrm{A} / \mathrm{T})$ in the DNA, resulting in the substitution of the glycine with a leucine in position 11 of the polypeptide chain of the TLR7 (Gln11Leu) (48). To evaluate whether the presence of this polymorphism may confer an increased susceptibility to $\mathrm{BCC}$, a case-control study was performed in which the distribution of frequencies of the wild-type and variant TLR7 carrying the SNP rs179008 in healthy subjects and in patients with $\mathrm{BCC}$ were analyzed. If the frequency of this polymorphism in patients with $\mathrm{BCC}$ had been greater compared to the healthy subjects, the SNP rs179008 of TLR7 could be considered as a cofactor in the carcinogenesis of BCC. The present results, however, do not suggest the involvement of the SNP rs179008 of TLR7 in the susceptibility to BCC, but cannot exclude a role for TLR7 in BCC initiation and progression. As a TLR7 agonist (imiquimod) shows a high therapeutic efficacy in the treatment of BCC, this indicates that alterations of this receptor can be implicated in the carcinogenesis of BCC. Exogenous factors may alter the function of this TLR leading to a defect of the innate immunity response. In this regard, it has been demonstrated that heat-shock proteins (49) and microRNAs (50) are ligands for TLR7 and that exogenous factors, in particular UV radiations, may deregulate their expression (51,52). As a consequence, under certain circumstances the TLR7 expression can be downregulated, diminishing its activity toward innate and acquired immunity, and consequently, also toward the control of UV-induced skin cancers.

In conclusion, although the genetic alteration of the TLR7 promoter does not appear to be associated with the development of BCC, a role of TLR7 cannot be excluded. Further genetic and functional studies of this receptor and its ligands may increase the knowledge in the mechanisms underlying the carcinogenic process of BCC and other UV-related skin cancers.

\section{References}

1. Bahner JD and Bordeaux JS: Non-melanoma skin cancers: Photodynamic therapy, cryotherapy, 5-fluorouracil, imiquimod, diclofenac, or what? Facts and controversies. Clin Dermatol 31: 792-798, 2013.

2. Madan V, Lear JT and Szeimies RM: Non-melanoma skin cancer. Lancet 375: 673-685, 2010.

3. Christenson LJ, Borrowman TA, Vachon CM, Tollefson MM Otley CC, Weaver AL and Roenigk RK: Incidence of basal cell and squamous cell carcinomas in a population younger than 40 years. JAMA 294: 681-690, 2005.

4. Dummer R, Karpova MB and Barysch MJ: Basal cell carcinomas: Molecular abnormalities and molecularly targeted therapies. Expert Rev Dermatol 4: 355-369, 2009.

5. Rippey JJ: Why classify basal cell carcinomas? Histopathology 32 : 393-398, 1998.

6. Rubin AI, Chen EH and Ratner D: Basal-cell carcinoma. N Engl J Med 353: 2262-2269, 2005.

7. Akira S and Hemmi H: Recognition of pathogen associated molecular patterns by TLR family. Immunol Lett 85: 85:95, 2003.

8. Miyake K: Innate immune sensing of pathogens and danger signals by cell surface Toll-like receptors. Semin Immunol 19: 3-10, 2007

9. Iwasaki A and Medzhitov R: Toll-like receptor control of the adaptive immune responses. Nat Immunol 5: 987-995, 2004.

10. Medzhitov R: Toll-like receptors and innate immunity. Nat Rev Immunol 1: 135-145, 2001.

11. Burns EM and Yusuf N: Toll-like receptors and skin cancer. Front Immunol 5: 135, 2014.

12. Kutikhin AG: Association of polymorphisms in TLR genes and in genes of the Toll-like receptor signaling pathway with cancer risk. Hum Immunol 72: 1095-1116, 2011.

13. Basith S, Manavalan B, Yoo TH, Kim SG and Choi S: Roles of Toll-like receptors in cancer: A double-edged sword for defense and offense. Arch Pharm Res 35: 1297-1316, 2012.

14. Eiró N, Ovies C, Fernandez-Garcia B, Alvarez-Cuesta CC, González L, González LO and Vizoso FJ: Expression of TLR3, 4, 7 and 9 in cutaneous malignant melanoma: Relationship with clinicopathological characteristics and prognosis. Arch Dermatol Res 305: 59-67, 2013.

15. Ermertcan AT, Öztürk F and Gündüz K: Toll-like receptors and skin. J Eur Acad Dermatol Venereol 25: 997-1006, 2011.

16. Diebold SS, Kaisho T, Hemmi H, Akira S and Reis e Sousa C: Innate antiviral responses by means of TLR7-mediated recognition of single-stranded RNA. Science 303: 1529-1531, 2004.

17. Gupta AK, Cherman AM and Tyring SK: Viral and nonviral uses of imiquimod: A review. J Cutan Med Surg 8: 338-352, 2004

18. Tyring S, Conant M, Marini M, Van Der Meijden W and Washenik K: Imiquimod; an international update on therapeutic uses in dermatology. Int J Dermatol 41: 810-816, 2002.

19. Tengroth L, Millrud CR, Kvarnhammar AM, Kumlien Georén S, Latif $\mathrm{L}$ and Cardell LO: Functional effects of Toll-like receptor (TLR)3, 7, 9, RIG-I and MDA-5 stimulation in nasal epithelial cells. PLoS One 9: e98239, 2014 
20. Zhang Y, Yang H, Barnie PA, Yang P, Su Z, Chen J, Jiao Z, Lu L, Wang $\mathrm{S}$ and $\mathrm{Xu} \mathrm{H}$ : The expression of Toll-like receptor 8 and its relationship with VEGF and Bcl-2 in cervical cancer. Int J Med Sci 11: 608-613, 2014

21. zur Hausen H: Condylomata acuminata and human genital cancer. Cancer Res 36: 794, 1976.

22. Parsonnet J, Friedman GD, Vandersteen DP, Chang Y Vogelman JH, Orentreich N and Sibley RK: Helicobacter pylori infection and the risk of gastric carcinoma. N Engl J Med 325: 1127-1131, 1991.

23. Bargen JA: Chronic ulcerative colitis associated with malignant disease. 1928. Dis Colon Rectum 37: 727-730, 1994.

24. Beasley RP, Hwang LY, Lin CC and Chien CS: Hepatocellular carcinoma and hepatitis B virus. A prospective study of 22707 men in Taiwan. Lancet 2: 1129-1133, 1981.

25. Huang B, Zhao J, Li H, He KL, Chen Y, Chen SH, Mayer L, Unkeless JC and Xiong H: Toll-like receptors on tumor cells facilitate evasion of immune surveillance. Cancer Res 65 5009-5014, 2005.

26. Schmausser B, Andrulis M, Endrich S, Müller-Hermelink HK and Eck M: Toll-like receptors TLR4, TLR5 and TLR9 on gastric carcinoma cells: An implication for interaction with Helicobacter pylori. Int J Med Microbiol 295: 179-185, 2005.

27. Droemann D, Albrecht D, Gerdes J, Ulmer AJ, Branscheid D, Vollmer E, Dalhoff K, Zabel P and Goldmann T: Human lung cancer cells express functionally active Toll-like receptor 9 . Respir Res 6: 1, 2005.

28. Helminen O, Huhta H, Takala H, Lehenkari PP, Saarnio J, Kauppila JH and Karttunen TJ: Increased Toll-like receptor 5 expression indicates esophageal columnar dysplasia. Virchows Arch 464: 11-18, 2014

29. Jouhi L, Renkonen S, Atula T, Mäkitie A, Haglund C and Hagström J: Different Toll-like receptor expression patterns in progression toward cancer. Front Immunol 5: 638, 2014

30. Fukata M, Chen A, Vamadevan AS, Cohen J, Breglio K, Krishnareddy S, Hsu D, Xu R, Harpaz N, Dannenberg AJ, et al: Toll-like receptor- 4 promotes the development of colitis-associated colorectal tumors. Gastroenterology 133: 1869-1881, 2007.

31. He W, Liu Q, Wang L, Chen W, Li N and Cao X: TLR4 signaling promotes immune escape of human lung cancer cells by inducing immunosuppressive cytokines and apoptosis resistance. Mol Immunol 44: 2850-2859, 2007.

32. Okamoto M, Oshikawa T, Tano T, Ohe G, FuruichiS, Nishikawa H, Ahmed SU, Akashi S, Miyake K, Takeuchi O, et al: Involvement of Toll-like receptor 4 signaling in interferon-gamma production and antitumor effect by streptococcal agent OK-432. J Nat Cancer Inst 95: 316-326, 2003.

33. Lowe EL, Crother TR, Rabizadeh S, Hu B, Wang H, Chen S, Shimada K, Wong MH, Michelsen KS and Arditi M: Toll-like receptor 2 signaling protects mice from tumor development in a mouse model of colitis-induced cancer. PLoS One 5: e13027, 2010.

34. Matijevic T, Marjanovic M and Pavelic J: Functionally active Toll-like receptor 3 on human primary and metastatic cancer cells. Scand J Immunol 70: 18-24, 2009.

35. Bauer AK, Dixon D, DeGraff LM, Cho HY, Walker CR, Malkinson AM and Kleeberger SR: Toll-like receptor 4 in butylated hydroxytoluene-induced mouse pulmonary inflammation and tumorigenesis. J Natl Cancer Inst 97: 1778-1781, 2005 .
36. Krieg AM: Antitumor applications of stimulating Toll-like receptor 9 with $\mathrm{CpG}$ oligodeoxynucleotides. Curr Oncol Rep 6: 88-95, 2004.

37. Aspord C, Tramcourt L, Leloup C, Molens JP, Leccia MT, Charles J and Plumas J: Imiquimod inhibits melanoma development by promoting pDC cytotoxic functions and impeding tumor vascularization. J Invest Dermatol 134: 2551-2561, 2014.

38. Wang J, Kobayashi M, Han M, Choi S, Takano M, Hashino S, Tanaka J, Kondoh T, Kawamura K and Hosokawa M: MyD88 is involved in the signalling pathway for Taxol-induced apoptosis and TNF-alpha expression in human myelomonocytic cells. Br J Haematol 118: 638-645, 2002.

39. Schiaffo CE, Shi C, Xiong Z, Olin M, Ohlfest JR, Aldrich CC and Ferguson DM: Structure-activity relationship analysis of imidazoquinolines with Toll-like receptors 7 and 8 selectivity and enhanced cytokine induction. J Med Chem 57: 339-347, 2014.

40. Takeda K and Akira S: Toll-like receptors in innate immunity. Int Immunol 17: 1-14, 2005

41. Schön M and Schön MP: The antitumoral mode of action of imiquimod and other imidazoquinolines. Curr Med Chem 14: 681-687, 2007.

42. Quirk C, Gebauer K, De'Ambrosis B, Slade HB and Meng TC: Sustained clearance of superficial basal cell carcinomas treated with imiquimod cream 5\%: Results of a prospective 5-year study. Cutis 85: 318-324, 2010

43. Alessi SS, Sanches JA, Oliveira WR, Messina MC, Pimentel ER and Festa Neto C: Treatment of cutaneous tumors with topical 5\% imiquimod cream. Clinics (Sao Paulo) 64: 961-966, 2009.

44. Ruiz-Villaverde R, Sánchez-Cano D and Burkhardt-Pérez P Superficial basal cell carcinoma treated with imiquimod $5 \%$ topical cream for a 4-week period: A case series. J Eur Acad Dermatol Venereol 23: 828-831, 2009.

45. Gollnick H, Barona CG, Frank RG, Ruzicka T, Megahed M, Maus J and Munzel U: Recurrence rate of superficial basal cell carcinoma following treatment with imiquimod 5\% cream: Conclusion of a 5-year long-term follow-up study in Europe. Eur J Dermatol 18: 677-682, 2008.

46. Sterry W, Ruzicka T, Herrera E, Takwale A, Bichel J, Andres K, Ding L and Thissen MR: Imiquimod 5\% cream for the treatment of superficial and nodular basal cell carcinoma: Randomized studies comparing low-frequency dosing with and without occlusion. Br J Dermatol 147: 1227-1236, 2002.

47. Valins W, Amini S and Berman B: The expression of Toll-like receptors in dermatological diseases and the therapeutic effect of current and newer topical Toll-like receptor modulators. J Clin Aesthet Dermatol 3: 20-29, 2010.

48. Askar E, Ramadori G and Mihm S: Toll-like receptor 7 rs179008/Gln11Leu gene variants in chronic hepatitis C virus infection. J Med Virol 82: 1859-1868, 2010.

49. Wang R, Town T, Gokarn V, Flavell RA and Chandawarkar RY: HSP70 enhances macrophage phagocytosis by interaction with lipid raft-associated TLR-7 and upregulating p38 MAPK and PI3K pathways. J Surg Res 136: 58-69, 2006.

50. Chen X, Liang H, Zhang J, Zen K and Zhang CY: MicroRNAs are ligands of Toll-like receptors. RNA 19: 737-739, 2013.

51. Calapre L, Gray ES and Ziman M: Heat stress: A risk factor for skin carcinogenesis. Cancer Lett 337: 35-40, 2013.

52. Syed DN, Khan MI, Shabbir M and Mukhtar H: MicroRNAs in skin response to UV radiation. Curr Drug Targets 14: 1128-1134, 2013. 